\title{
Growth During the First Two Years Predicts Pre-School Height in Children Born With Very Low Birth Weight (VLBW): Results of a Study of 1,320 Children in Germany
}

\author{
BRANKO TREBAR, RICHARD TRAUNECKER, HANS-KONRAD SELBMANN, AND MICHAEL B. RANKE \\ Paediatric Endocrinology Section [B.T., R.T., M.B.R.], University Children's Hospital, D-72076 Tuebingen, Germany; Institute for \\ Medical Information Processing [H.-K.S.], D-72070 Tuebingen, Germany
}

\begin{abstract}
Children born with very low birth weight (VLBW) are at risk of impaired growth. We aimed to study VLBW survivors (90.8\%) born in 1998/1999 in the state of Baden-Württemberg ( $n=$ 2103) for whom growth data were available up to age six. Classification as appropriate for gestational age (AGA) or small for gestational age (SGA) depended on size at birth. Models to predict height SDS at 5 y were developed using data for $1 \mathrm{yr}$ (Model 1) and $2 \mathrm{yrs}$ (Model 2). The data of 1320 (63\%) children were available: SGA: $n=730$, AGA: $n=590$. At 6 yrs, $8.3 \%$ AGA and $13.4 \%$ SGA children were short $(<-2.0 \mathrm{SDS})$. The following factors explained Ht SDS at 5 (and 6) yrs (order of importance): (a) Model 1 ( $n=$ 1033; $\mathrm{R}^{2}=0.52$; error: 0.84 SDS): 1st yr Ht SDS, mid-parental height (MPH) SDS, $1^{\text {st }}$ yr weight SDS, birth weight SDS; (b) Model $2\left(n=991 ; \mathrm{R}^{2}=0.72\right.$; error: 0.65 SDS $): 1^{\text {st }}$ yr Ht SDS; change $\left(2^{\text {nd }}\right.$ $\mathrm{yr}$ ) in Ht and weight SDS; MPH SDS; $1^{\text {st }} \mathrm{yr}$ weight SDS; birth weight SDS. Thus, some AGA and SGA children born VLBW remain short and preventive strategies need to be developed for those at risk.
\end{abstract} (Pediatr Res 62: 209-214, 2007)

A lthough the frequency of premature births has risen during the last decades, the number of surviving babies has risen due to improved perinatal care. This holds particularly true for children with very low birth weight (VLBW; BW < $1500 \mathrm{~g}$ ), as their survival rate has reached about 90\% (1). Several reports have shown more frequent impairments in growth development in this group in comparison to other prematurely born children with higher birth weights (2-9). After Barker and colleagues established that low birth weight was a major determinant of mortality and morbidity in adult life (10), overwhelming evidence became available from epidemiologic studies which show that impaired birth weight is associated with a higher prevalence of the metabolic syndrome. It has therefore been hypothesized that an impairment in prenatal growth influences the long-term "metabolic programme" of an individual. Several authors have reported that children born small for gestational age (SGA) showed impaired growth in contrast to children whose birth length was appropriate for gestational age (AGA). However the main group studied in these reports involved either children with

Received March 15, 2007; accepted March 23, 2007.

Correspondence: Michael B. Ranke, M.D., Paediatric Endocrinology Section, University Children's Hospital, Hoppe-Seyler Strasse 1, D-72076 Tuebingen, Germany; e-mail: Michael.Ranke@med.uni-tuebingen.de

This work was supported by a grant from Novo Nordisk, Germany. birth weights higher than $1500 \mathrm{~g}(11-14)$ or VLBW children born earlier than $1990(3,5,6,15,16)$. Our study of VLBW children was aimed at investigating growth development from birth until early school age and at identifying the factors to predict their height development during childhood. The two birth cohorts we studied derived from the state birth register in Baden-Württemberg in Germany for the years 1998 and 1999, respectively.

\section{METHODS}

Population. The state of Baden-Wuerttemberg represents about $10 \%$ of Germany's geographical area and approximately $13 \%$ of its population. According to the state birth register, there were 108,000 births in 1998 and 111,000 in 1999 (17). Of these, 2316 VLBW babies were born and 2103 $(90.8 \%)$ of them survived (1). There are 30 neonatal intensive care units (NICU) in Baden-Wuerttemberg, including four university hospitals; and all excepting two small units participated in our study (see Acknowledgements).

Data collection. In 2004, birth and follow-up data were available for 2040 (97\%) surviving children born VLBW. Parents were sent a questionnaire and a description of the study by post. $1322(62.9 \%)$ families returned the questionnaire to the NICU at which their child was born; the information was made anonymous before being sent to us for analysis. This procedure complies with the German data protection laws. The study was approved by the Ethics Committee of the University of Tuebingen (Germany) [\#48/2004] and the Ethics Committee of the State Chamber of Physicians (Landesärztekammer Baden-Wuerttemberg, \# M-048-04).

Data on gestational age, date of birth, weight, length and head circumference at birth were extracted from birth records. Values for weight, length (height after $2 \mathrm{y}$ of age), and head circumference were taken, as documented by the family physician/paediatrician within the framework of the German paediatric examination ("Untersuchungen") system (18). These "U" measurements are scheduled at $6 \mathrm{wk}$ (U3), $16 \mathrm{wk}$ (U4), 6 mo (U5), 12 mo (U6), 24 mo (U7), 48 mo (U8) and 60 mo (U9). Since the measurement of anthropometrical parameters in this system is not standardised, each family was given a measuring tape (Schneider Massband No 819/10; accuracy $1 \mathrm{~mm}$ ) and instructions for measuring their child's as well as their own height. The mean variance between measurements by the parents and those done by our staff using an electronic stadiometer (Prof. Heinz Stadiometer, Ulm) $(n=35)$ was $0.9 \mathrm{~mm}$. We did not include parental measurements of head circumference, as they were inaccurate; in addition, head circumference data at 60 mo (U9) were unavailable.

Statistical analyses. Anthropometrical variables of birth weight, length and head circumference data were compared against references devised by Usher and McLean (19), and are expressed as SD scores relating to gestational age $(\mathrm{GA})$ : [SDS $=$ (parameter of patient minus mean of reference)/SD of mean of reference]. The extrapolation of SD scores for the data of neonates born $<25$ gestational weeks were based on Usher and McLean's references. Children with birth weight and/or birth length values below the $10^{\text {th }}$ centile ( $=-1.282$ SDS) were considered to be SGA. Swiss references (20) ethnically representative of our south German population were applied for

Abbreviations: AGA, appropriate for gestational age; MPH, mid-parental height; SGA, small for gestational age; VLBW, very low birth weight 
transforming postnatal anthropometrical data into age-related SD scores. Age values were adjusted for prematurity (GA minus age at the time of examination) up to age two. Mid-parental height (MPH) SD scores were calculated by averaging the height SD scores of both parents. Anthropometrical data are given here as means and SD scores. Quantitative variances between the groups were tested by means of ANOVA or unpaired $t$ tests. A $p<0.01$ was taken to indicate significance. Categorical variables were analyzed through the $\chi^{2}$ test and Fisher's exact test when indicated. Data were analyzed by means of SAS, JMP®.

Height prediction. Multiple regression analysis was used to study the correlation between height SD scores at 5 y of age (U9) and the following variables: (1) status at birth: sex, gestational age (GA), SD scores for weight, length and head circumference; (2) genetic background: SD scores for maternal height, paternal height and MPH; (3) variables at follow-up: SD scores at age 1 (U6) for length, weight and head circumference; and SD scores for gain in weight/length between age 1 and 2 (U6 to U7) and gain in head circumference. We developed prediction models through multiple linear regression analysis fitted by least squares and the REG procedure in the SAS computer programme (version 9.1.3, SAS Institute, Inc., Cary, N.C., USA). A hierarchy of predictive factors was derived by the all-possible regression approach, using Mallow's C(p) criterion for ordering predictive factors (21). Two models were generated: the first one applying data from birth to age one; the second model additionally included data up to age two. The method of Bland and Altman (22) was used to diagnose outliers, nonlinearity, and nonconstant error variance in the prediction models. Both models were recalculated by taking $50 \%$ random sample of the population (learning sample) and the remaining 50\% was used to validate the models.

\section{RESULTS}

Of the 2040 families of VLBW children, 1322 responded to our questionnaire. Due to discrepancies in gestational age in the documents of two children, they could not be classified as either SGA or AGA. Thus data on length/height were available for 1320 children at birth, 1254 at U6, 1230 at U7, 1191 at U8, 1102 at U9, and 1300 at follow-up (median age: $6.1 \mathrm{y}$; 95\% range: 4.9 to $7.3 \mathrm{y}$ ).

At birth. Anthropometrical characteristics at birth and MPH are listed in Table 1. Gestational age ranged from 22 to $38 \mathrm{wk}$ for SGA and from 23 to 32 wk for AGA. In our study, 99.5\% were born at 36 wk of gestation or earlier. The total VLBW group comprised 1320 infants (680 female, 640 male), and included 730 SGA (414 female, 316 male) and 590 AGA cases (female 266, 324 male). By definition, SD scores for length, weight and head circumference were significantly lower $(p<0.001)$ in the SGA cohort than in the AGA cohort. However, there was no difference between the cohorts in MPH SDS, with the values being similar to the reference population. On the whole, there were no statistically significant genderspecific differences between the SGA and AGA subgroups at birth (with the exception of head circumference in girls).

Postnatal development. Table 2 shows the parameters measured up to U9 in the SGA and AGA groups. SGA values were consistently and significantly lower $(p<0.001)$ than the AGA cohort. Whereas length/height SDS in the SGA group rose from -2.5 SDS (mean) at birth to -1.1 SDS at U6 ( $p<$

Table 1. Characteristics of population at birth

\begin{tabular}{|c|c|c|c|c|c|c|c|}
\hline & \multicolumn{2}{|c|}{$\begin{array}{c}\text { All } n=1320 \\
\text { Female, } 680 \\
\text { Male, } 640\end{array}$} & \multicolumn{2}{|c|}{$\begin{array}{c}\text { SGA } n=730 \\
\text { Female, } 414 \\
\text { Male, } 316\end{array}$} & \multicolumn{2}{|c|}{$\begin{array}{c}\text { AGA } n=590 \\
\text { Female, } 266 \\
\text { Male, } 324\end{array}$} & \multirow{2}{*}{$\begin{array}{c}\text { SGA } \\
\text { vs. } \\
\text { AGA } \\
p\end{array}$} \\
\hline & Mean & $\mathrm{SD}$ & Mean & SD & Mean & $\mathrm{SD}$ & \\
\hline Gestational age [Weeks] & 29.17 & 2.79 & 29.89 & 3.10 & 28.28 & 2.03 & $<0.001$ \\
\hline Weight $[\mathrm{g}]$ & 1097 & 278 & 1031 & 300 & 1178 & 222 & $<0.001$ \\
\hline Weight [SDS] & -1.16 & 1.42 & -2.11 & 1.00 & 0.02 & 0.85 & $<0.001$ \\
\hline Length $[\mathrm{cm}]$ & 37.02 & 3.71 & 36.06 & 4.15 & 38.23 & 2.62 & $<0.001$ \\
\hline Length [SDS] & -1.33 & 1.88 & -2.47 & 1.62 & 0.09 & 1.03 & $<0.001$ \\
\hline Head circumference $[\mathrm{cm}]$ & 26.60 & 2.85 & 26.49 & 3.07 & 26.73 & 2.56 & 0.160 \\
\hline Head circumference [SDS] & -0.32 & 1.72 & -0.97 & 1.51 & 0.50 & 1.61 & $<0.001$ \\
\hline Midparental height [SDS] & 0.08 & 0.86 & 0.06 & 0.87 & 0.10 & 0.85 & 0.363 \\
\hline
\end{tabular}

Table 2. Postnatal characteristics

\begin{tabular}{|c|c|c|c|c|c|c|c|c|c|}
\hline \multirow[b]{2}{*}{ Age (timepoint) } & \multirow[b]{2}{*}{ Group } & \multirow[b]{2}{*}{$n$} & \multicolumn{2}{|c|}{$\begin{array}{l}\text { Height/length } \\
\text { [SDS] }\end{array}$} & \multirow{2}{*}{$\begin{array}{l}\text { Height/length } \\
<-2.0 \mathrm{SDS} \%\end{array}$} & \multicolumn{2}{|c|}{$\begin{array}{l}\text { Weight } \\
\text { [SDS] }\end{array}$} & \multicolumn{2}{|c|}{$\begin{array}{c}\text { Head } \\
\text { circumference } \\
{[\text { SDS }]}\end{array}$} \\
\hline & & & Mean & SD & & Mean & $\mathrm{SD}$ & Mean & SD \\
\hline \multirow[t]{3}{*}{$0.8 \mathrm{yr}(\mathrm{U} 6)$} & All & 1254 & -0.75 & 1.43 & 16.7 & -1.19 & 1.34 & -0.78 & 1.33 \\
\hline & SGA & 701 & -1.12 & 1.42 & 22.8 & -1.54 & 1.35 & -1.06 & 1.35 \\
\hline & AGA & 553 & -0.27 & 1.29 & 9.4 & -0.74 & 1.18 & -0.42 & 1.21 \\
\hline \multirow[t]{3}{*}{1.8 yrs (U 7) } & All & 1230 & -0.69 & 1.33 & 13.3 & -1.28 & 1.42 & -0.87 & 1.30 \\
\hline & SGA & 689 & -1.00 & 1.31 & 19.0 & -1.57 & 1.47 & -1.15 & 1.29 \\
\hline & AGA & 541 & -0.30 & 1.25 & 5.9 & -0.91 & 1.27 & -0.52 & 1.24 \\
\hline \multirow[t]{3}{*}{4.0 yrs (U 8) } & All & 1191 & -0.93 & 1.22 & 18.2 & -1.32 & 1.65 & -1.12 & 1.32 \\
\hline & SGA & 664 & -1.10 & 1.22 & 21.1 & -1.59 & 1.70 & -1.36 & 1.31 \\
\hline & AGA & 527 & -0.71 & 1.20 & 14.6 & -0.97 & 1.51 & -0.81 & 1.27 \\
\hline \multirow[t]{3}{*}{5.2 yrs (U 9) } & All & 1102 & -0.76 & 1.21 & 14.1 & -1.06 & 1.52 & & \\
\hline & SGA & 608 & -0.94 & 1.19 & 16.6 & -1.31 & 1.56 & & \\
\hline & AGA & 494 & -0.54 & 1.19 & 10.9 & -0.76 & 1.41 & & \\
\hline \multirow[t]{3}{*}{6.1 year (follow-up) } & All & 1300 & -0.62 & 1.23 & 11.1 & -0.85 & 1.72 & & \\
\hline & SGA & 721 & -0.78 & 1.23 & 13.4 & -1.09 & 1.57 & & \\
\hline & AGA & 579 & -0.42 & 1.21 & 8.3 & -0.54 & 1.84 & & \\
\hline
\end{tabular}




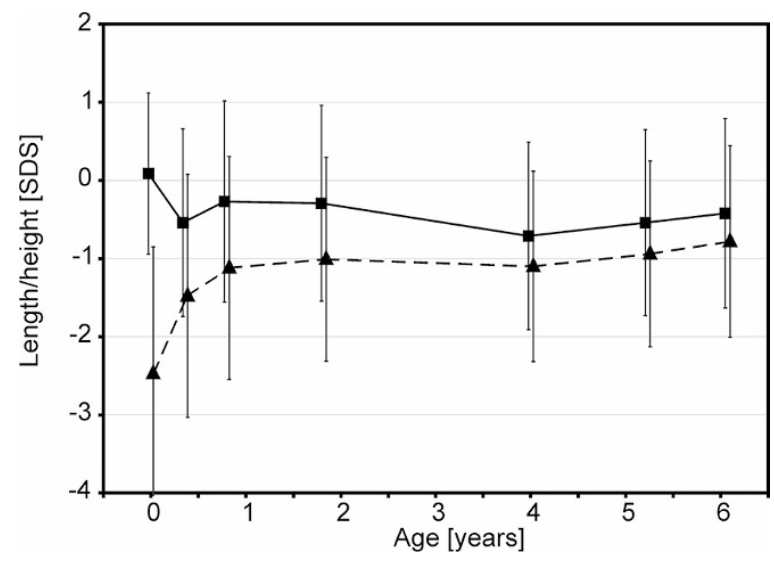

Figure 1. Mean height of children born SGA (dashed line) or AGA (solid line) in relation to chronological age (vertical line $=1 \mathrm{SD}$ ).

0.001 ), gradually increasing to $-0.9 \mathrm{SDS}$ at $\mathrm{U} 9$ and to -0.8 SDS at follow up, in the AGA cohort it declined from 0.1 SDS (mean) at birth to -0.3 SDS at U6 $(p<0.001)$, and then gradually decreased to $-0.5 \mathrm{SDS}$ at $\mathrm{U} 9$ and to $-0.4 \mathrm{SDS}$ at follow up. Height SDS at U9 strongly correlated with height SDS at follow-up $(\mathrm{R}=0.93 ; p<0.001)$. Height was below -2.0 SDS in $16.6 \%$ and $13.4 \%$ cases in the SGA group and in $10.9 \%$ and $8.3 \%$ in the AGA cohort at U9 and at follow-up $(p<0.001)$. The median age and range for height measurements done at home by the parents was $6.1(4.9-7.3)$ year. There were minor changes in the SD scores for height between U9 (5.2 yrs) and follow-up (6.1 yrs). The pattern of height development was similar (Table 2). The pattern of length/ height SDS in the two cohorts is depicted in Fig. 1. Head circumference decreased gradually from $-1.0 \mathrm{SDS}$ at birth to -1.4 SDS at U8 in the SGA cohort $(p<0.001)$, and decreased from 0.5 SDS at birth to -0.8 SDS at U8 in the AGA cohort $(p<0.001)$. Thus there was a difference in the pattern of postnatal development of the three anthropometrical variables between the two cohorts.

Up to U6 there was no difference between boys and girls in the SGA and AGA cohorts. However, at U8 and later, boys tended to be shorter, lighter and have a lower head circumference, in the SGA as well as in AGA group (Table 3).
After subdividing the two groups according to height outcome (above or below $-2.0 \mathrm{SDS}$ ) at U9, differences in the growth patterns emerged (Table 4). There were 87 (15.9\%) SGA children below and 459 above the score, whereas in the AGA group $47(11.1 \%)$ were below and 376 above, respectively. (Results pertain exclusively to children for whom data for all parameters were available). There were no differences in gestational age within each group. Children in the SGA group with short parents had a low height outcome and gained less length and weight SDS during the first year in comparison to those with height outcomes in the normal range. Some AGA children also had small parents. Our results showed that decrease in length and weight SDS during the first year was higher than in AGA children whose height was in the normal range. These analyses indicate that the degree of catch-up growth during the early postnatal years strongly influences childhood height. The percentage of smallness (length/height below - 2.0 SDS) during childhood development is illustrated in Fig. 2.

Growth predictors and prediction models. Two prediction models for height SDS at age 5 (U9) were established. In the first model (M1), explanatory variables available at age one (U6) were considered; in the second model (M2) all explanatory variables available up to age 2 (U7) were involved. All explanatory variables were considered significant if the $\mathrm{P}$ was $<0.005$. Explanatory variables that showed no influence on the models included gestational age, birth length, sex, and head circumference. Table 5 shows the predictors and their specific contributions to the models.

The first model (M1) was based on four predictors (in order of importance): height SDS at U6, MPH SDS, weight SDS at U6, birth weight SDS. They accounted for 52\% of the variance with an error of 0.84 SDS. The regression equation for height SDS at U9 (M1) is: Ht SDS U9 $=-0.312+$ [length $\mathrm{U} 6(\mathrm{SDS}) \times 0.398]+[\mathrm{MPH}(\mathrm{SDS}) \times 0.341]+[$ weight $\mathrm{U} 6$ $(\mathrm{SDS}) \times 0.203]+$ [birth weight $(\mathrm{SDS}) \times-0.060]$.

The second model (M2) was based on six predictors (in order of importance): height SDS at U6, change in height SDS from U6 to U7, change in weight SDS from U6 to U7, MPH SDS, weight SDS at U6, birth weight SDS. They accounted for $72 \%$ of the

Table 3. Postnatal characteristics (gender related)

\begin{tabular}{|c|c|c|c|c|c|c|c|}
\hline Age (years) & Group & Gender & $n$ & \multicolumn{2}{|c|}{ Height* [SDS] } & \multicolumn{2}{|c|}{ Weight* $[$ SDS $]$} \\
\hline \multirow[t]{3}{*}{4.0 years } & SGA & Female & 371 & -0.91 & 1.26 & -1.15 & 1.30 \\
\hline & AGA & Female & 241 & -0.49 & 1.23 & -0.64 & 1.26 \\
\hline & & Male & 288 & -0.89 & 1.14 & -1.25 & 1.64 \\
\hline \multirow[t]{2}{*}{5.2 years } & SGA & Female & 338 & -0.83 & 1.24 & -1.05 & 1.35 \\
\hline & & Male & 259 & -0.71 & 1.09 & -0.97 & 1.50 \\
\hline \multirow[t]{4}{*}{6.1 years } & SGA & Female & 409 & $-0.70 \dagger$ & 1.29 & -0.85 & 1.39 \\
\hline & & Male & 312 & $-0.88 \dagger$ & 1.12 & -1.41 & 1.74 \\
\hline & AGA & Female & 259 & -0.25 & 1.32 & -0.22 & 2.14 \\
\hline & & Male & 320 & -0.57 & 1.09 & -0.80 & 1.52 \\
\hline
\end{tabular}

* The differences between gender are significant, $p<0.001$.

$\dagger p=0.054$. 
Table 4. Characteristics of children born SGA or AGA according to height outcome at 5 years of age

\begin{tabular}{|c|c|c|c|c|c|c|c|c|c|c|}
\hline \multirow[b]{2}{*}{ Height SDS at 5 yrs of age } & \multicolumn{5}{|c|}{ SGA } & \multicolumn{5}{|c|}{ AGA } \\
\hline & Mean & SD & Mean & SD & $p$ & Mean & SD & Mean & SD & $p$ \\
\hline Birth weight [SDS] & -2.55 & 1.19 & -2.01 & 0.95 & $<0.001$ & 0.00 & 0.77 & 0.00 & 0.81 & 1.000 \\
\hline Gestational age [week] & 29.09 & 3.18 & 30.26 & 2.93 & $<0.001$ & 27.49 & 2.06 & 28.46 & 1.92 & 0.0013 \\
\hline $2^{\text {nd }}$ yr height gain $[\Delta$ SDS $]$ & 0.26 & 1.05 & 0.10 & 0.95 & 0.157 & -0.25 & 0.92 & 0.04 & 0.98 & 0.055 \\
\hline $1^{\text {st }} \mathrm{yr}$ weight gain $[\Delta$ SDS $]$ & -0.17 & 1.32 & 0.73 & 1.22 & $<0.001$ & -1.83 & 1.23 & -0.60 & 1.22 & $<0.001$ \\
\hline 2nd yr weight gain $[\Delta$ SDS $]$ & -0.44 & 0.80 & 0.03 & 0.71 & $<0.001$ & -0.54 & 0.74 & -0.09 & 0.74 & $<0.001$ \\
\hline
\end{tabular}

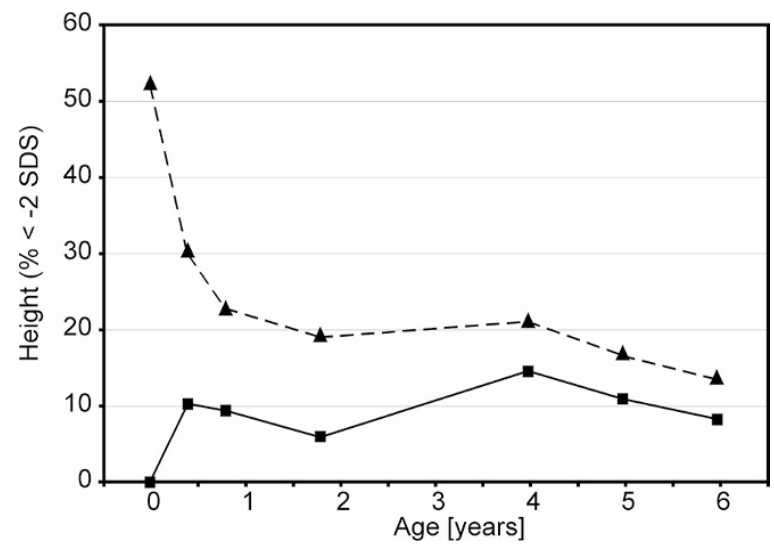

Figure 2. Percentage of children with height $<-2.0$ SDS at age 5 , showing infants born SGA (dashed line) and AGA (solid line).

variance with an error of 0.65 SDS. The regression equation for height SDS at U9 (M2) is: Ht SDS U9 $=-0.234+$ [length U6 $(\mathrm{SDS}) \times 0.616]+[\Delta$-height U7-U6 $(\mathrm{SDS}) \times 0.489]+$ $[\Delta$-weight U7-U6 $(\mathrm{SDS}) \times 0.314]+[\mathrm{MPH}(\mathrm{SDS}) \times 0.208]+$ [weight U6 (SDS) $\times 0.156]+$ [birth weight $($ SDS $) \times-0.073$ ]

Validation of the models. We used two methods to validate the models. The first was the Bland and Altman method (22), which uses predicted height and the observed height SDS at U9: it showed no discrepancies in the relation to the magnitude of height or outliers. However, if height values are greater, it is likely that a small underestimation in predicted height emerges, which is statistically unremarkable if the numbers of cases are about 1,000. Secondly, we re-calculated both models by using a 50\% random sample from the U9 group and the resulting model was applied to the remaining $50 \%$ of the same group. Figure 3 shows scatter plots for predicted versus. observed height at U9 for the 50\% learning sample and the $50 \%$ validation sample for model 2 . A covariance analysis showed no statistically significant difference $(p<0.001)$ between both regression lines in both models.

The prediction models for U9 (5.2 yrs) were also used to predict the height at follow-up (6.1 yrs). The regression equation for the follow-up value and the predicted height at U9 was: Ht SDS $(6.1 \mathrm{yrs})=(0.130+0.976 \times \mathrm{Ht}$ SDS $)(\mathrm{U} 9)$. The intercept indicates the slight increase in height SDS between year 5 and 6 .

\section{DISCUSSION}

Increasing numbers of premature children survive in the developed countries (23-25) owing to improvements in perinatal care $(1,26,27)$, among them being $90 \%$ with a birth weight $<1500 \mathrm{~g}$ (VLBW). The long-term implications of prematurity have led to several questions being raised, in particular with regard to health impairments and height outcome. Investigations of the somatic development of these children gained importance after permanent short stature was observed in a fraction of children born SGA (11-14); for whom growth hormone treatment is meanwhile accepted practice (28). The focus on this group intensified after Barker and colleagues showed that smallness at birth was the strongest predictor of the metabolic syndrome in mature adult life (29). Most investigations were based on the data of children with

Table 5. Regression equations of height prediction height for age 5 (U9) based on first year (M1) and up to second year (M2) variables

\begin{tabular}{|c|c|c|c|c|}
\hline \multirow[b]{2}{*}{ Predictors } & \multicolumn{2}{|c|}{$\begin{array}{c}\text { Model 1 } \\
(n=1033) \\
\mathrm{R}^{2}=0.520 \\
\mathrm{SD}[\mathrm{SDS}]=0.840\end{array}$} & \multicolumn{2}{|c|}{$\begin{array}{c}\text { Model 2 } \\
(n=991) \\
\mathrm{R}^{2}=0.716 \\
\mathrm{SD}[\mathrm{SDS}]=0.646\end{array}$} \\
\hline & Parameter estimate & Partial $\mathrm{R}^{2}$ & Parameter estimate & Partial $\mathrm{R}^{2}$ \\
\hline Intercept & -0.312 & & -0.234 & \\
\hline Height U6 [SDS] & 0.398 & 0.448 & 0.616 & 0.448 \\
\hline Parental height [SDS] & 0.341 & 0.050 & 0.208 & 0.018 \\
\hline Weight U6 [SDS] & 0.203 & 0.019 & 0.156 & 0.009 \\
\hline Birth weight [SDS] & -0.06 & 0.004 & -0.073 & 0.006 \\
\hline
\end{tabular}



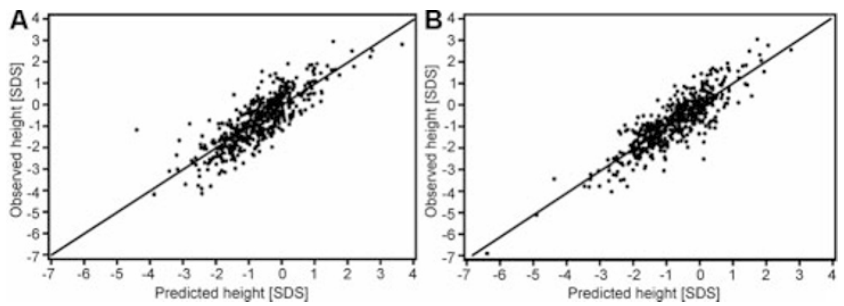

Figure 3. Correlation between predicted (x) and observed height SDS at $5 \mathrm{y}$ (y) in the 50\% learning sample $(n=496)$, and in the validation sample $(n=495)$. (A) Model 2, learning sample: $\mathrm{y}=\mathrm{x}$; (B) validation sample: $\mathrm{y}=0.03+1.02 \mathrm{x}$.

low birth weight, i.e., 1500-2500 g. Since VLBW is associated with several adverse events during the perinatal stage (ventilation problems, infections, insufficient nutrition), we hypothesized that impairments in the somatic outcome of these children would be identifiable not only in SGA but also in AGA children.

Ours is the first study on a complete VLBW cohort over 2 successive years in a German state, thus being a representative sample. We had datasets for 1320 (62.9\%) out of 2040 survivors born VLBW (97\% of VLBW births). Our approach involved the collection and analysis of anthropometrical measurements from the family physicians' records (18) as well as those taken by the family following our instructions. This approach has proved to be practical and methodologically acceptable. The references applied in our analysis are widely accepted by German neonatologists (19) and/or are truly representative for the south-western region of Germany we studied (20).

We observed rapid catch-up in the total cohort during the first year, followed by gradual height increment subsequently. The proportion of short children $(<-2$ SDS) was $14.1 \%$ at age 5 and $11.1 \%$ at age 6 . Our findings showed that, while the SGA cohort mainly caught up during the first year, $16.6 \%$ continued to be short at age 5 and $13.4 \%$ at age 6 . In the AGA cohort, $10.9 \%$ were short at age 5 and $8.3 \%$ at age 6 . These findings confirm the results of other investigators $(3,15,16)$. VLBW children born SGA tended to be short at $5 / 6$ y of age if low height gain occurred during the first year of life, if no substantial weight gain was observed during that time and if their parents were relatively short. VLBW children born AGA also tended to be short at 5/6 y of age if height/weight gain was not appropriate during the first two years and also if their parents were shorter than their counterparts in the study.

As in our study, some investigators of height development in very premature children focused on growth and development up to early school age $(4,5,8,9,30,31)$. Others followed their subjects up to higher ages $(3,15,32)$, and very few studied adults (premature at birth) $(6,7,16,33,34)$. Although catch-up growth can occur after the age of 5 or 6 (32), most authors presume that little height gain ensues if height is diminished at the age of $5(15,33)$ or 8 y $(6,33)$. European authorities have not approved of GH treatment in SGA children before age 4, a decision based on the assumption that catch-up may occur.

Several studies have attempted the prediction of height outcome in children born with low birth weight. Kitchen et al. (4) analyzed an Australian cohort of 135 VLBW children at age 5, with height below the 10th centile in $34(25 \%)$ children at age two and $31(23 \%)$ children at age five. Multivariate analyses at age 5 showed that the most important predictor was height at age 2. In a further study (35) involving 165 VLBW children, the authors reported that height in $56(34 \%)$ children was below the 10th centile at age 2 and 33 (59\%) children were below the 10th centile at age 5 . Their study suggested that prenatal variables were stronger determinants of growth failure during childhood than ill health after birth.

Qvigstad et al. (31) analyzed 565 VLBW children (up to 5 y of age) from a national survey in the Netherlands. In $32 \%$ of the SGA children, height was below the 10th centile, compared with 23\% in the AGA group. Using the 5th centile as the cut-off, the respective percentages were $26 \%$ and $22 \%$. Their results showed that $85 \%$ of the variability (height $<10$ th centile) could be predicted (all parameters correlated positively) by length at $1 \mathrm{y}$, height at $2 \mathrm{y}$, weight at two years, parental height, parental level of education and hypertension during pregnancy.

Ours is the first study of a very large cohort of VLBW children, from a homogeneous region, which aimed at predicting height at the age of 5 (and 6) years. We took the "all possible regression approach" which allows the calculation of the independent effect of easily accessible anthropometrical variables at ages 1 and 2 . The predicted variability for these regression equations was high at $52 \%$ for age one and $72 \%$ for age 2; and involved a low margin of error. The most important predictors were height at age one and the difference in height between ages 1 and 2 . Thus, these prediction equations make it possible - with a high degree of certainty - to identify the children likely to achieve normal height by the time of school admission, as well to differentiate those children who are likely to remain short. More importantly, such differentiation is essential for further improvements in the structure and organisation of paediatric examination systems for children born prematurely. Since height gain between 5 and $6 \mathrm{y}$ of age is negligible, the models can also be applied to height prediction for age 6. Based on these algorithms it may be predicted that children who are very short at age two are unlikely to reach normal height during childhood. Our data support the concept of Wit et al. 2006 (36) that the preterm growth restraint in some prematurely born AGA children leads to permanent short stature.

Acknowledgments. This study is the result of a statewide survey conducted by the Paediatric Endocrinology Section of the University Children's Hospital Tuebingen, Germany. Other participating physicians and centres were: A. Artlich, B. Keyser, Oberschwabenklinik Ravensburg; M. Brandis, K.O. Schwab, Universitätsklinikum Freiburg; K.M. Debatin, H.D. Hummler, Universitätsklinikum Ulm; W. Ertelt, A. Schneider, Klinikum Heidenheim; J.U. Folkens, J. Hautz, Klinikum Offenburg; J. Forster, R. Sauter, St. Josefs Krankenhaus Freiburg; J. Freihorst, G. Saur, Ostalb-Klinikum Aalen; R. Huenges, Klinikum Villingen-Schwenningen; W. Kachel, A. Ruland, SLK-Kliniken Heilbronn; J. Kuehr, Städtisches Klinikum Karlsruhe; O. Linderkamp, H.-J. Gausepohl, Universitätsklinikum Heidelberg; W. Nützenadel, S. Gonzalves, Univer- 
sitätsklinikum Mannheim; C.J. Partsch, Städtische Kliniken Esslingen a.N.; C. Poets, Universitätsklinikum Tübingen; U. Radlow, K. Placzek, Städtisches Krankenhaus Friedrichshafen; K. Rager, H. Knüppel, Caritas-Krankenhaus Bad Mergentheim; U. Rappen, A. Keller, Stadtklinik Baden-Baden; H.L. Reiter, W. Koch, Klinikum Pforzheim; G. Schädel, C. Bultmann, Margaritenhospital Schwäbisch Gmünd, H.U. Schwenk, H. Schmidt, Klinikum Konstanz and Hegau Klinikum Singen; M. Stahl, M. Luther, Kreiskrankenhaus Lörrach; G. Strotbek, A. Weimann, Kreiskrankenhaus Waiblingen; M. Teufel, G. Froese, Kreiskrankenhaus Böblingen; F. Trefz, H. Schneider, Klinikum am Steinenberg Reutlingen; M. Vochem, E. Kuhls, Olgahospital Klinikum Stuttgart; M. Walka, Klinikum Ludwigsburg; D. Wölfel, D. Richter, Klinik am Eichert Göppingen.

We are grateful to Dipl. Biol. C. Engel for her valuable advice and for conducting the statistical analysis. We would also like to thank P.M. Weber for preparing the graphics and P. Herrmann for her editorial assistance. This work was supported by a grant from Novo Nordisk, Germany.

\section{REFERENCES}

1. Hentschel R 1998 [Neonatal survey in Baden-Wuerttemberg: complete statistical data for the year 1998]. Chamber of Physicians of the State of Baden-Wuerttemberg, $1-16$

2. Hack M, Flannery DJ, Schluchter M, Cartar L, Borawski E, Klein N 2002 Outcomes in young adulthood for very-low-birth-weight infants. N Engl J Med 346:149-157

3. Hack M, Weissman B, Borawski-Clark E 1996 Catch-up growth during childhood among very low-birth-weight children. Arch Pediatr Adolesc Med 150:1122-1129

4. Kitchen WH, Ford GW, Doyle LW 1989 Growth and very low birth weight. Arch Dis Child 64:379-382

5. Vohr BR, Oh W 1983 Growth and development in preterm infants small for gestational age. J Pediatr 103:941-945

6. Hack M, Schluchter M, Cartar L, Rahman M, Cuttler L, Borawski E 2003 Growth of very low birth weight infants to age 20 years. Pediatrics 112:e30-e38

7. Ericson A, Kallen B 1998 Very low birthweight boys at the age of 19. Arch Dis Child Fetal Neonatal Ed 78:F171-F174

8. Binkin NJ, Yip R, Fleshood L, Trowbridge FL 1988 Birth weight and childhood growth. Pediatrics 82:828-834

9. Casey PH, Kraemer HC, Bernbaum J, Tyson JE, Sells JC, Yogman MW, Bauer CR 1990 Growth patterns of low birth weight preterm infants: a longitudinal analysis of a large, varied sample. J Pediatr 117:298-307

10. Barker DJ, Winter PD, Osmond C, Margetts B, Simmonds SJ 1989 Weight in infancy and death from ischaemic heart disease. Lancet 2:577-580

11. Karlberg J, Albertsson-Wikland K 1995 Growth in full-term small-for-gestationalage infants: from birth to final height. Pediatr Res 38:733-739

12. Strauss RS, Dietz WH 1997 Effects of intrauterine growth retardation in premature infants on early childhood growth. J Pediatr 130:95-102

13. Hediger ML, Overpeck MD, McGlynn A, Kuczmarski RJ, Maurer KR, Davis WW 1999 Growth and fatness at three to six years of age of children born small- or large-for-gestational age. Pediatrics 104:e33
14. Hokken-Koelega AC, De-Ridder MA, Lemmen RJ, Den-Hartog H, de-MuinckKeizer S, Drop SL 1995 Children born small for gestational age: do they catch up? Pediatr Res 38:267-271

15. Knops NB, Sneeuw KC, Brand R, Hille ET, den Ouden AL, Wit JM, VerlooveVanhorick SP 2005 Catch-up growth up to ten years of age in children born very preterm or with very low birth weight. BMC Pediatr 5:26

16. Peralta-Carcelen M, Jackson DS, Goran MI, Royal SA, Mayo MS, Nelson KG 2000 Growth of adolescents who were born at extremely low birth weight without major disability. J Pediatr 136:633-640

17. State Statistics Office Baden-Württemberg 2006 [Marriages, live births and death in Baden-Wuerttemberg since 1950.] Stuttgart, State Statistics Office BadenWürttemberg. Report LRt0106, 1

18. Federal Joint Committee 1976 [Guidelines for the early detection of diseases in children up to six years of age]. Federal Gazette (Bundesanzeiger); Report No. 214 28

19. Usher R, McLean F 1969 Intrauterine growth of live-born Caucasian infants at sea level: standards obtained from measurements in 7 dimensions of infants born between 25 and 44 weeks of gestation. J Pediatr 74:901-910

20. Prader A, Largo RH, Molinari L, Issler C 1989 Physical growth of Swiss children from birth to 20 years of age. First Zurich longitudinal study of growth and development. Helv Paediatr Acta Suppl 52:1-125

21. Weisberg S 1985 Applied linear regression, Wiley and Sons, Chichester

22. Bland JM, Altman DG 1999 Measuring agreement in method comparison studies. Stat Methods Med Res 8:135-160

23. Martin JA, Hamilton BE, Ventura SJ 2001 Births: preliminary data for 2000. Natl Vital Stat Rep 49:1-20

24. Kramer MS, Barros FC, Demissie K, Liu S, Kiely J, Joseph KS 2005 Does reducing infant mortality depend on preventing low birthweight? An analysis of temporal trends in the Americas. Paediatr Perinat Epidemiol 19:445-451

25. Macfarlane AJ, Mugford M 2000 Birth Counts: statistics of pregnancy and childbirth. The Stationary Office, London

26. Rettwitz-Volk W 2002 Indices of birthweight-specific perinatal mortality in Germany from 1985 to 1999. Paediatr Perinat Epidemiol 16:383-385

27. Kaiser JR, Tilford JM, Simpson PM, Salhab WA, Rosenfeld CR 2004 Hospital survival of very-low-birth-weight neonates from 1977 to 2000. J Perinatol 24:343350

28. de Zegher F, Du Caju MV, Heinrichs C, Maes M, De Schepper J, Craen M, Vanweser K, Malvaux P, Rosenfeld RG 1999 Early, discontinuous, high dose growth hormone treatment to normalize height and weight of short children born small for gestational age: results over 6 years. J Clin Endocrinol Metab 84:15581561

29. Barker DJ, Eriksson JG, Forsen T, Osmond C 2002 Fetal origins of adult disease strength of effects and biological basis. Int J Epidemiol 31:1235-1239

30. Ross G, Lipper EG, Auld PA 1990 Growth achievement of very low birth weight premature children at school age. J Pediatr 117:307-309

31. Qvigstad E, Verloove-Vanhorick SP, Ens-Dokkum MH, Schreuder AM, Veen S, Brand R, Oostdijk W, Ruys JH 1993 Prediction of height achievement at five years of age in children born very preterm or with very low birth weight: continuation of catch-up growth after two years of age. Acta Paediatr 82:444-448

32. Ford GW, Doyle LW, Davis NM, Callanan C 2000 Very low birth weight and growth into adolescence. Arch Pediatr Adolesc Med 154:778-784

33. Hirata T, Bosque E 1998 When they grow up: the growth of extremely low birth weight $(<$ or $=1000 \mathrm{gm})$ infants at adolescence. J Pediatr 132:1033-1035

34. Saigal S, Stoskopf BL, Streiner DL, Burrows E 2001 Physical growth and current health status of infants who were of extremely low birth weight and controls at adolescence. Pediatrics 108:407-415

35. Kitchen WH, Doyle LW, Ford GW, Callanan C 1992 Very low birth weight and growth to age 8 years. I: Weight and height. Am J Dis Child 146:40-45

36. Wit JM, Finken MJ, Rijken M, de Zegher F 2006 Preterm growth restraint: a paradigm that unifies intrauterine growth retardation and preterm extrauterine growth retardation and has implications for the small-for-gestational-age indication in growth hormone therapy. Pediatrics 117:e793-e795 